\title{
Morphological Awareness of Connective Endings in 1st through 4th Grade Children with and without Language Delay from Culturally Diverse Families
}

\author{
Seoung-Eun Shima ${ }^{\mathrm{a}}$, Bhu Ja Chung ${ }^{\mathrm{b}}$ \\ ${ }^{a}$ Korea Child-Family Counseling Center, Gwangju, Korea \\ ${ }^{b}$ Department of Speech-Language Pathology, Chosun University, Gwangju, Korea
}

Correspondence: Bhu Ja Chung, PhD Department of Speech-Language Pathology, Chosun University, 309 Pilmun-daero, Dong-gu, Gwangju 61452, Korea

Tel: $+82-62-230-7858$

Fax: +82-62-230-6271

E-mail: bjchung@chosun.ac.kr

Received: April 20, 2019

Revised: May 23, 2019

Accepted: May 29, 2019

This work was supported by research fund from Chosun University, 2018.

This article is based on a data from the first author's master's thesis.
Objectives: Culturally diverse family in Korea usually refers to a family consisting of a married Korean citizen and a foreign spouse. Despite the rapid increase of culturally diverse families and acknowledgement of the limited linguistic stimuli for children in those populations, few studies have demonstrated proper research evidence for evaluation and intervention in various language-related areas. Morphological awareness has been recognized as a critical metalinguistic skill relevant to vocabulary acquisition and literacy development. The purpose of this study was to investigate the relation of linguistic competence to morphological awareness of connective endings, one of the unique bound morphemes in Korean, in school-aged Korean-speaking children. Methods: The participants were 38 lower grade children (1st and 2 nd grade) and 40 upper grade children (3rd and 4th grade) from three groups: typical children from non-culturally diverse families (TND), typical children from culturally diverse families (TCD) which are language-matched with TND, and language impaired children from culturally diverse families (LCD). Results: The results showed that the significant difference of morphological awareness appeared between TCD and TND in lower grades, but was not found in upper grades. LCD, however, consistently performed lower than TND on the morphological awareness test in both grade levels. Although positive growth in morphological awareness across grades appeared in each of the three groups, LCD remained far below TCD and TND. Conclusion: The study findings revealed that cultural background made a contribution to morphological awareness during the initial period of school years, but longitudinal associations between morphological awareness and linguistic competence lasted even through the late school years.

Keywords: Connective endings, Morphological awareness, Culturally diverse, School-aged children
1990년대 이후 국제결혼의 비율과 외국인 노동자의 유입이 증가 하면서 우리나라는 점차 다양한 민족이 함께 살아가는 다문화사회 로 변화하고 있다. 이러한 변화는 결혼이민자의 수가 2007년 142,015 명에서 2015년 305,446명으로 늘어났으며 이와 함께 만 18세 이하 다문화가정 아동의 수도 약 4.5 배 증가하였다는 행정안전부(Ministry of the Interior and Safety, 2015)의 다문화가족 인구조사 결과 로도 알 수 있다. 학령기 다문화가정 아동이 증가함에 따라 이들이 경험하는 학업상의 어려움이나 높은 중도 탈락률, 또래 집단에서
경험하는 소외나 정서적 문제 등이 사회적 관심사로 대두되고 있는 데 국내외 선행연구들은 언어적 지원의 결핍을 그 원인의 하나로 지적하고 있다(Brice \& Montgomery, 1996; Jeong, Kim, \& Park, 2012; Kim \& Lee, 2016; Kouider, Koglin, \& Petermann, 2015). 언어 적 및 문화적 환경의 측면에서 서구의 연구들은 대부분 다중언어 사용 아동을 대상으로 진행이 되었으며(Goldstein, Fabiano, \& Washington, 2005; Zhang, Koda, \& Leong, 2016), 외국인 가정뿐 아니라 국제결혼 사례가 다문화가정의 대부분을 차지하는 국내에 
서도 아동의 이중언어습득을 지원하는 정책이 꾸준히 진행되고 있 다. 그러나 지역사회 및 교육 환경에 적응하기 위해서는 여전히 유 창한 한국어를 습득할 필요가 더 큰 편이다. 따라서 이들 아동을 대상으로 한국어에 고유한 문법적 요소를 인식하고 활용하는 것 에 관한 체계적인 연구가 지속될 필요가 있다. 지금까지 진행된 국 내연구들에 의하면 비유언어(Choi \& Hong, 2012), 동음이의어(Jang, Jeong, \& Hwang, 2014), 연어(Jo, Hwang, \& Jeong, 2018) 및 전제의 미추론(Hwang, Hwang, \& Lim, 2019)과 같이 깊이 있는 언어지식 을 요하는 과제나 시제 및 문법형태소(Choi, 2011; Kim, 2012; Song \& Kim, 2011), 형태인식(Kim \& Jung, 2015)과 같이 세부적인 문법 적 지식이 필요한 항목에서 다문화가정 아동들이 제한된 수행을 보인다고 보고하는 경우가 주를 이루었다. 그러나 아동들의 학년이 나 연령이 증가함에 따라 비다문화가정 아동과의 격차가 유의하게 줄어드는 영역이 존재한다는 연구도 꾸준히 제시되고 있다(Kim \& Lee, 2016).

다문화가정 아동이 제한된 수행을 보인다고 보고된 언어영역 중 형태인식(morphological awareness)이란 단어 수준의 언어 구조에 관한 상위언어인식의 하나로 형태소에 대해 의식적으로 생각하고, 인식하며, 그 구조를 조작하는 능력을 의미한다(Carlisle, 1995). 형 태인식은 기본형의 단어에 다른 단어의 어근, 혹은 접사나 어미를 결합하는 과정을 익힌 후 이를 적용하여 익숙하지 않은 단어의 의 미와 발음을 유추 및 조작하는 과제를 사용해 평가할수 있다(Green, 2009; Kim \& Jung, 2015). 굴절어 및 파생어 형태인식의 징후는 학 령전기부터 나타나나 아동이 언어의 형식과 의미의 복잡한 관계에 대해 이해하기 시작하는 초등학교 시기부터 구체적이고 본격적으 로 형태소 조작과 활용에 관한 인식이 발달하게 된다(Anglin, 1993; Carlisle, 2000; Chung, 2016). 따라서 형태인식은 많은 경우 음운인 식(Deacon \& Kirby, 2004; Gibson \& Wolter, 2015), 단어재인 및 해 독(Nagy, Berninger, \& Abbott, 2006; Sparks \& Deacon, 2015) 등과 같은 다양한 읽기 요소와 관련하여 그 유의성이 탐색되어 왔고 (Carlisle, 1995; Jung, 2014; Kirby et al., 2012; Nagy \& Anderson, 1999) 형태인식 중재 또한 철자 및 읽기이해능력의 증진에 기여한 다고 보고되었다(Kirk \& Gillon, 2009; Wolter \& Dilworth, 2014). 또한 형태소라는 의미단위를 이해하고 분석하는 능력에 기반한 형 태인식은 그 특성상 어휘의 발달과 관련이 깊으며(Bowers \& Kirby, 2010; Gibson \& Wolter, 2015; Ramirez, Walton, \& Roberts, 2014), 어휘력의 증진에 유의하게 관여함으로써 읽기 기술을 매개하는 변 인이라고 설명되기도 하였다(Nagy et al., 2006). Kieffer와 Lesaux (2012)도 형태인식의 발달과 어휘지식 사이의 강한 관련성뿐 아니 라 형태인식의 성장속도가 빠른 학생들이 어휘의 성장 또한 빠르
게 보였음을 보고하였다.

아동이 낮설고 복잡한 형태의 어휘를 읽거나 들었을 때 형태인식 이라는 상위언어 기술을 적용하여 해당 어휘의 기본적인 의미와 접미사나 어미의 의미를 반영하여 이를 추론하고 새로운 어휘를 생성해내는 기술은 고학년이 되면서 점차 중요해진다(Anglin, 1993; McBride-Chang et al., 2008). 따라서 그러한 전략을 적절히 적용하는 기술이 부족한 아동은 상대적으로 제한된 어휘지식을 지니게 될 것이라는 추론도 가능해진다. 그렇다면 읽기나 어휘의 발달과 관련이 깊은 형태인식 전략을 적용하는 능력은 환경적 요인 보다는 언어발달상의 기질적 결함과 상관이 있는 기술인가? 선행 연구들은 다문화가정 아동들이 학령기에도 여전히 언어 및 문법적 인 지식을 요하는 과제에서 어려움을 보인다고 보고한 바 있다 (Choi \& Hong, 2012; Hwang et al., 2019; Kim \& Lee, 2016). 형태인 식영역에서도 비다문화가정 아동에 비해 여러 형태인식 과제에서 상대적으로 수행수준이 낮았으며, 이러한 낮은 수행수준이 해독, 읽기유창성 및 읽기이해 능력과 유의한 상관을 보이는 것으로 나타 났다(Kim \& Jung, 2015). 하지만 형태인식 관련 연구들은 초등 1-3 학년을 한 집단으로 분석하거나(Kim \& Jung, 2015) 저학년 비다문 화가정 아동을 대상으로 진행하였으므로(Chung, 2017; Jung, 2014), 다문화가정 아동들을 다양한 학년에 걸쳐 살펴보고 언어적 어려 움이 있는 아동과의 집단 비교를 진행하지 않았다는 점에서 다소 한계가 있다.

조사나 어미 변화가 풍부한 교착어인 한국어에서는 정교하고 세 련된 문장을 구성하기 위해 문법형태소를 정확히 이해하고 활용하 는 것이 매우 중요하다. 그중 연결어미는 문장의 응집성을 형성하고 복잡한 문장을 구성하는 데에 필수적이고(Chung, 2013; Park, Kim, \& Yeon, 2018; Song, 2016) 종결어미나 전성어미 등과 같은 다 른 형태소에 비해 의미가 다양하며 수가 많아 저학년에 비해 고학 년이, 중학생에 비해 고등학생이 다양한 연결어미를 높은 빈도로 사용한다(Im \& Lee, 2004). 따라서 일반적인 용언의 활용능력이 6 세경에 안정화되고 정확도가 향상되긴 하지만(Chung, 2013; Jang \& Kim, 2014), 연결어미는 경도지적장애(Cha, Hwang, \& Jeong, 2018), 단순언어장애(Park et al., 2018)와 같이 언어적 취약성을 지 닌 아동들이 꾸준히 어려움을 보이는 문법형태소의 하나이다. 그 러나 지금까지 다문화가정 아동이 보이는 연결어미 형태인식에 관 하여 그 발달적 추이를 살펴보거나 혹은 타 집단과 비교를 실시한 연구는 매우 제한적이었다(Kim \& Chung, 2017). 따라서 본 연구 는 구문형태적 문법지식이 본격적으로 성숙하기 시작하는 초등 1-2학년과 지속적인 문법지식의 발달과정에 있는 3-4학년 아동을 대상으로 하였다. 이는 해당 학년 다문화가정 아동과 유사한 언어 
및 문화적 환경을 지닌 다문화가정 언어발달지연 아동을 비다문화 가정 아동과 함께 비교함으로써 아동집단마다 학년에 따라 그 수 행에 발달적 차이가 있는지 살펴보고자 함이었다. 또한 학년에 따 른 아동집단 간의 차이를 분석함으로써 연결어미 형태인식이 다문 화가정이라는 환경에 의해 영향을 받는 요인인지 아니면 기질적인 언어적 결함과 좀 더 관련 있는 상위언어적 요인의 하나인지 파악 하고자 하였다. 본 연구에서 밝혀진 다문화가정 아동의 형태인식에 관한 내용이 이후 아동에게 명시적인 문법지식을 중재하고자 할 때 기초자료로 활용되기를 기대하였다.

\section{연구방법}

\section{연구대상}

본 연구는 광주광역시 및 호남 지역에 거주하는 초등학교 1학년 부터 4 학년 비다문화가정 정상언어아동(typical children from non-culturally diverse families, TND) 29명, 다문화가정 정상언어 아동(typical children from culturally diverse families, TCD) 29명, 그리고 다문화가정 언어발달지연아동(language impaired children from culturally diverse families, LCD) 20 명, 총 78 명의 아동을 대 상으로 하였다. 다문화가정 아동의 경우 '부모의 출신 국적별 다문 화 학생 현황 조사결과'(Ministry of the Interior and Safety, 2015) 를 참고하여 어머니의 국적이 가장 많은 비율을 차지하는 순서대로 중국, 일본, 베트남, 필리핀의 4 개 국가로 제한하였다. 연구대상 아 동의 선정 기준은 다음과같다.

세 집단 아동은 모두 (1) 한국비언어지능검사-2판(Korean Comprehensive Test of Nonverbal Intelligence-2, K-CTONI-2; Park, 2014) 결과 비언어성지능이 80 이상으로 정상 범주에 속하며, (2) 부 모 혹은 교사로부터 사회, 정서, 행동, 청력 및 기타 감각기관에 문 제를 보이지 않는다고 보고되었다. 비언어지능의 경우 수행점수
70-79를 경계선 지능으로, 80-89를 보통 하 지능으로 명시한 WISCIV 임상해석기준(Weiss, Saklofske, Prifitera, \& Holdnack, 2006) 및 동일 기준을 적용한 선행연구를 참고하여 비언어지능 80 이상 에 해당하는 아동을 연구대상자로 선정하였다(Choi \& Shin, 2018; Lee \& Kim, 2015). 그중 TND 집단은 (1) 부모가 모두 한국인이며, (2) 수용·표현 어휘력검사(Receptive \& Expressive Vocabulary Test, REVT; Kim, Hong, Kim, Jang, \& Lee, 2009)의 수용어휘검사 결과 생활연령의 -1 표준편차 이상으로 정상발달범주에 해당하는 아동으로 선정하였다. TCD 집단은 (1) 아버지가 한국인이고 어머 니가 상기 4 개 국가에서 이주한 경우로서 한국에 거주하며 주언어 로 한국어를 사용하는 아동으로, (2) REVT 결과 수용어휘가 -1 표 준편차 이상이었다. $\mathrm{LCD}$ 집단은 TCD 집단 기준의 (1)과 동일하되, (2) REVT 결과 수용어휘가 - 1 표준편차 미만으로 언어발달지연에 속하는 아동으로 선정하였다. 또한 TND 집단과 TCD 집단의 경우 $\mathrm{TCD}$ 집단 아동이 보인 REVT 수용어휘검사의 원점수에서 \pm 5 점 의 원점수를 보인 TND 집단 아동들로 동일 학년 내에서 $1: 1$ 매칭을 하였다. 이는 두 집단 아동의 언어능력을 일치시킴으로써 두 집단이 가정의 문화적 배경에서만 차이를 보이도록 통제하기 위함이었다.

본 연구에 참여한 아동 집단에 대한 기술통계 결과는 Table 1과 같다. 학년집단은 1 학년과 2 학년을 저학년으로, 3 학년과 4 학년을 중학년으로 나누었고 평균 개월수, 비언어성 지능 및 수용어휘 점 수에 따른 차이를 분산분석한 결과 모든 학년에서 집단 간에 개월 수와 비언어성 지능에서 유의한 차이를 보이지 않는 것으로 나타났 다. REVT 수용어휘검사에서는 저학년과 중학년 모두에서 집단 간 차이가 유의하였고, 사후검정을 실시한 결과 저학년과 중학년에서 모두 TND 집단과 TCD 집단 간에는 차이를 보이지 않았으며 LCD 집단은 TND 및 $\mathrm{TCD}$ 집단과 유의한 차이를 보이는 것으로 나타났 다(수용어휘-저학년 TND vs. LCD $F=4.2727, p<.001$; TCD vs. $\mathrm{LCD} F=6.423, p<.001$; 중학년 TND vs. LCD $F=4.914, p<.01$;

Table 1. Participants' characteristics

\begin{tabular}{|c|c|c|c|c|c|c|c|c|}
\hline & \multicolumn{2}{|c|}{ TND (N=29) } & \multicolumn{2}{|c|}{$\operatorname{TCD}(\mathrm{N}=29)$} & \multicolumn{2}{|c|}{$\operatorname{LCD}(\mathrm{N}=20)$} & \multicolumn{2}{|c|}{$p$-value } \\
\hline & Lower $(N=14)$ & Middle $(N=15)$ & Lower $(\mathrm{N}=14)$ & Middle $(N=15)$ & Lower $(\mathrm{N}=10)$ & Middle $(\mathrm{N}=10)$ & Lower & Middle \\
\hline Age (mo) & $87.57(7.49)$ & $107.46(9.56)$ & $86.35(6.75)$ & $107.86(4.99)$ & $87.60(7.30)$ & $110.80(6.81)$ & .876 & .515 \\
\hline C-TONI-2 (raw score) & 99.57 (8.94) & $100.53(12.15)$ & $102.14(8.00)$ & 97.66 (11.64) & $94.90(5.74)$ & $100.50(13.26)$ & .098 & .777 \\
\hline REVT-R (raw score) & $85.50(10.70)$ & $100.20(11.44)$ & $85.35(10.06)$ & $100.06(12.71)$ & $62.50(10.11)$ & $80.50(11.83)$ & .000 & .000 \\
\hline & & & & & & & $\begin{array}{c}\text { TND }=\text { TCD } \\
L C D<T N D, T C D\end{array}$ & $\begin{array}{c}\text { TND }=\text { TCD } \\
\mathrm{LCD}<\mathrm{TND}, \mathrm{TCD}\end{array}$ \\
\hline
\end{tabular}

Values are presented as mean (SD).

TND = typical children from non-culturally diverse families; TCD=typical children from culturally diverse families; $L C D=$ language impaired children from culturally diverse families; Lower=group with 1st and 2nd grades; Middle=group with 3rd and 4th grades; C-TONI-2=Korean Comprehensive Test of Nonverbal Intelligence-second edition; REVT-R=Receptive \& Expressive Vocabulary Test-Receptive subtest. 
TCD vs. $\operatorname{LCD} F=4.914, p<.01)$.

\section{연구도구 및 절차}

연구도구의 제작 및 타당도

연결어미의 경우 의미관계(예: 계기, 조건)는 한정되나, 의미관계 에 포함되는 연결어미(예: '-려고', '-도록')는 그 수와 난이도가 매우 다양하므로 연구대상자의 연령을 고려하여 각 의미관계에 해당하 는 연결어미를 선택하여야 한다. 학교문법에서는 보통 대등적, 종 속적, 보조적 연결어미의 셋으로 연결어미를 분류하나, 본 연구에 서는 이를 문법적 특성에 따라 구별하는 것이 용이하지 않다는 의 견(Yi, 2015)을 참고하였고 다양한 난이도를 지닌 연결어미를 검사 에 반영할 필요도 있었다. 따라서 세부적으로 '계기', '조건', '보조 (-고)', '부정', ‘이유·원인, '목적, '시간·동시', '결과', '선택', '대립.대 조, '전환', '배경', '양보'의 총 13 개 의미관계에 따라 연결어미를 선 택하였다. 이 의미관계와 연결어미는 본 연구 대상자와 비슷하거나 높은 연령대를 대상으로 한 Im과 Lee (2004), Kim과 Chung (2017), Park (2014)에서 해당 연령대에서 주로 사용한다고 보고된 것들이 었다. 검사형식으로는 선행연구(Kim, 2015)에서 변별력이 있는 것 으로 나타난 ‘빈칸 채우기' 형식을 사용하여 의미관계에 해당하는 연결어미마다 연습문항을 1 개씩 제공하여 해당 형태소에 관하여 조작하는 방식을 익히도록 하였다. 또한 연결어미 형태인식 검사에 서 사용한 문장의 형식과 길이는 선행연구를 참고하여 4-5어절로 한정하였다(Chang, 2011; Kim \& Chung, 2017). 본 연구의 검사문 항 내 모든 어휘는 초등학교 교과서 어휘조사연구(Kwon, 2009)를 참고로 1-2학년 교과서에 실린 어휘를 선정하거나, $\operatorname{Kim}$ (2003)의 어휘목록을 참고로 난이도가 쉬운 1,2 등급의 어휘로 구성하였다. 예시 문항의 어휘는 모두 '가다'로 통일하였으며, 본 문항의 어휘들 은 서로 중복되지 않도록 하였다.

최초 문항 개발 시 언어병리학교수 1 인과 국어국문학박사 1 인의 검토하에 각 의미관계에 해당하는 하나의 연결어미(이후 연결어미) 당 8 개, 총 104 개의 문항을 개발하였다. 그 후 초등학교 담임교사에 게 의뢰하여 학업수준이 평균에 속하며 기타 장애가 없는 1 학년부 터 4 학년까지 학년당 2 명씩 총 8 명 아동을 선정하여 예비검사를 실 시하였고, 문항의 난이도와 적절성을 평가하는 과정을 거쳐 2 차로 13 개의 연결어미당 5 문항씩 총 65 문항으로 조정하였다. 해당 문항에 대한 내용타당도는 Fehring (1987)의 점수별 가중치를 적 용하는 Likert 5 점 척도를 사용하여 언어병리학 박사과정 4 인, 1 급 언어재활사 2 인, 총 6 인에게 의뢰하였고 .88 의 결과를 얻을 수 있었 다. 최종적으로 제작된 연결어미 형태인식 검사기록지의 의미관계 별 문항 예는 Appendix 1에 제시하였다.

\section{연구절차}

연결어미 형태인식검사는 PPT로 제작하여 노트북으로 아동에 게 제시하였다. 학년에 따라 읽기 수준이 다름을 고려하여 각 검사 문항의 문장이 시각적으로 제시됨과 동시에 녹음파일이 재생되도 록 하였다. 제시 문장 사이의 빈칸은 '삐 ’와 같은 1 초간의 기계음 으로 채워 아동이 목표어휘(예: 가다)를 조작하여야 함을 인식하도 록 하였으며, 외부소음을 통제하고자 재생된 녹음파일을 헤드폰으 로 들려주었다(“이제부터 선생님이 단어와 문장을 보여 줄게요. 문 장의 빈칸, 즉 ‘삐' 소리가 나는 부분에 위에 나오는 단어를 바꿔서 알맞게 넣어주면 돼요”).

본 연구는 대상 아동이 속한 초등학교 및 지역아동센터의 복지 실, 도서관, 교실 등의 조용한 환경에서 개별적으로 진행하였다. 어 휘 및 지능검사, 연결어미 형태인식검사는 무작위 순서로 실시하였 으며 대상자의 반응을 모두 현장에서 기록 및 녹음하였다.

\section{자료분석 및 신뢰도}

채점 시 아동이 문장 전체를 말하거나 목표어휘만 정확히 말한 경우 모두 정반응으로 처리하였고, 아동이 표현한 연결어미가 목표 연결어미가 아닌 경우에는 문장의 의미가 적절하더라도 오반응으 로 처리하였다(예: 목표가 ‘-사면'인 경우 아동 반응 ‘과일을 많이 사니까 무거워요'는 오반응으로 처리). 검사는 정반응 1 점, 오반응 0 점으로 총 65점으로 채점하였다. 자료분석에는 IBM SPSS version 23.0 을 사용였고, 아동집단 간 연결어미 형태인식능력의 차이를 알 아보기 위해 일원변량분석(One-way ANOVA)을 각 아동집단 내 학년집단 간의 차이를 알아보기 위해 비모수검정인 맨-휘트니 검 정(Mann-Whitney test)을 실시하였다. 이는 각 아동 집단 내 학년 집단의 수가 10 명에서 15 명으로 정규분포를 가정하는 $t$-검정을 적 용하기에는 표본의 크기가 충분하지 않으므로 비모수검정을 실시 하는 것이 적절하다고 판단되었기 때문이다.

검사 후 제 1 평가자인 연구자와 제 2 평가자인 언어병리학 전공자 이고 2년 이상 임상경험을 지닌 대학원생이 전체 녹음자료의 $20 \%$ 를 무선 추출하여 각자 분석한 뒤 일치율을 확인함으로써 검사자 간 신뢰도를 분석하였다. 그 결과 연결어미 형태인식검사에서 $100 \%$ 의 일치율을 얻을 수 있었다.

\section{연구결과}

본 연구에서 수집한 각 아동집단과 아동집단 내 학년집단이 보 인 연결어미 형태인식검사 점수에 관한 평균 및 표준편차의 기술통 계 결과는 Table 2에 제시된 바와 같다. 
Table 2. Descriptive statistics of morphological awareness of connective endings

\begin{tabular}{lllll}
\hline & TND $(\mathrm{N}=29)$ & TCD $(\mathrm{N}=29)$ & $\mathrm{LCD}(\mathrm{N}=20)$ & Total $(\mathrm{N}=78)$ \\
\hline Lower & $35.92(12.85)$ & $21.50(10.02)$ & $16.90(9.66)$ & $25.60(13.53)$ \\
Middle & $51.00(9.14)$ & $48.20(12.71)$ & $38.20(13.42)$ & $46.75(12.49)$ \\
Total & $43.72(13.31)$ & $35.31(17.66)$ & $27.55(15.77)$ & $36.44(16.74)$ \\
\hline
\end{tabular}

Values are presented as mean (SD) and raw scores.

TND = typical children from non-culturally diverse families; $T C D=$ typical children from culturally diverse families; $L C D=$ language impaired children from culturally diverse families; Lower=group with 1st and 2nd grades; Middle=group with 3rd and 4th grades.

\section{아동집단 내 연결어미 형태인식의 학년 간 차이}

$\mathrm{TND}, \mathrm{TCD}$, 그리고 LCD 집단 내에서 학년 간 연결어미 형태인 식검사 점수에 유의한 차이가 보이는지 분석하기 위해 비모수검정 인 맨-휘트니 검정을 실시하였다. 분석결과 TND 집단 $(U=40.500$, $p<.01), \mathrm{TCD}$ 집단 $(U=11.500, p<.001)$, 그리고 $\mathrm{LCD}$ 집단 $(U=11.000$, $p<.01)$ 모두 저학년과 중학년 집단 간에 연결어미 형태인식검사 점 수에서 학년 간 차이가 유의한 것으로 나타났다. 이는 다문화 배경 이나 언어적 지연 여부에 상관없이 연결어미를 활용하고 조작하는 형태인식 능력은 학년이 증가함에 따라 함께 발달하는 상위언어지 식이라는 의미로 해석될 수 있다. 검정결과는 Table 3에 제시된 바 와같다.

\section{학년집단에 따른 아동집단 간 연결어미 형태인식}

$\mathrm{TND}, \mathrm{TCD}$, 그리고 LCD 집단에 속한 저학년 아동들의 연결어 미 형태인식이 집단에 따라 차이를 보이는지 살펴보기 위해 일원 분산분석을 실시하였다. 분석 결과 세 집단 간에 유의한 차이가 있 는 것으로 나타났다 $\left(F_{(2,35)}=10.12, p<.001\right)$. 이러한 결과가 어느 집 단 간의 차이에 기인하는지 알아보기 위해 Turkey 사후검정을 실 시한 결과 $\mathrm{TND}$ 집단과 $\mathrm{TCD}$ 집단 $(p<.01)$ 그리고 $\mathrm{TND}$ 집단과 $\mathrm{LCD}$ 집단 $(p<.001)$ 간에 유의한 차이가 나타났으나, TCD 집단과 $\mathrm{LCD}$ 집단 간에는 유의한 차이가 발견되지 않았다 $(p=.580)$. 이는 저학년 아동집단에서는 언어지연 여부에 상관없이 다문화가정이 라는 문화적 배경을 공통적으로 지닌 아동들의 연결어미 형태인식 능력이 비다문화가정 아동들에 비해 더 낮은 양상을 보였음을 의 미하는 결과라 할 수 있다.

다음으로 중학년에 속한 TND, TCD, 그리고 $\mathrm{LCD}$ 집단 아동들 간의 연결어미 형태인식의 차이를 살펴보기 위해 마찬가지로 일원 분산분석을 실시하였다. 그 결과 .05의 유의도 수준에서 저학년에 서와 마찬가지로 세 아동집단 간에 유의한 차이가 있는 것으로 나 타났다 $\left(F_{(2,37)}=3.782, p<.05\right)$. 이러한 차이가 유의하였으므로 Tur-
Table 3. Results of Mann-Whitney test on morphological awareness of connective endings

\begin{tabular}{lrrccc}
\hline & Median & Range & $U$ & $Z$ & $p$-value \\
\hline $\operatorname{TND}(\mathrm{N}=29)$ & 45.000 & $12-64$ & 40.500 & -2.817 & .004 \\
$\operatorname{TCD}(\mathrm{N}=29)$ & 36.500 & $5-64$ & 11.500 & -3.963 & .000 \\
$\operatorname{LCD}(\mathrm{N}=20)$ & 27.550 & $3-61$ & 11.000 & -2.958 & .002 \\
\hline
\end{tabular}

TND = typical children from non-culturally diverse families, lower grade $(N=14)+$ middle grade $(N=15) ; T C D=$ typical children from culturally diverse families, lower grade $(N=14)+$ middle grade $(N=15)$; $L C D=$ language impaired children from culturally diverse families, lower grade $(\mathrm{N}=10)+$ middle grade $(\mathrm{N}=10)$.

$\mathrm{key}$ 사후검정을 실시한 결과 $\mathrm{TND}$ 집단과 $\mathrm{TCD}$ 집단 $(p=.790)$, 그 리고 TCD 집단과 $\mathrm{LCD}$ 집단 $(p=.105)$ 은 그 차이가 유의한 것으로 나타나지 않았으나, TND 집단과 LCD 집단 간의 차이는 유의한 것 으로 분석되었다 $(p<.05)$. 이러한 분석내용은 저학년에서 보인 사 후검정 결과와 비교할 때 매우 흥미로운 추이를 보여주고 있다. 즉, 저학년 시기에는 사후검사 결과 언어지연 여부보다 다문화가정이 라는 요인을 공유한 $\mathrm{TCD}$ 집단과 $\mathrm{LCD}$ 집단이 동질적인 집단으로 나타나고, 언어능력은 유사하게 통제하되 문화적 요인이 유일한 차 이인 TND 집단과 TCD 집단이 유의한 차이를 보였다. 그러나 학년 이 높아지면서 언어능력을 일치시킨 TND 집단과 TCD 집단이 유 의한 차이를 보이지 않는 동질적인 집단으로 분석되었다. 이는 연령 이나 학년이 증가함에 따라 다문화가정 아동이 정상적인 범주의 언어능력을 지닌 경우 연결어미 형태인식검사에서 점진적으로 향 상된 수행을 보이며 비다문화가정 아동들과 유사한 양상을 나타내 나, 언어발달이 지연된 아동의 경우 여전히 연결어미 형태인식검사 수행에서 상대적으로 저조한 수준을 유지하는 경향을 의미하는 결과라는 해석을 가능케 한다.

마지막으로 전체 학년에서 세 집단 간의 연결어미 형태인식의 차 이를 살펴보기 위해 일원분산분석을 실시한 결과 세 집단 간의 차 이가 유의한 것으로 분석되었다 $\left(F_{(2,75)}=6.423, p<.01\right)$. 이러한차이 가 어느 집단 간에 나타나는지 확인하기 위해 위와 마찬가지로 Turkey 사후검정을 실시하였을 때 중학년에서 보인 결과와 유사하 게 TND 집단과 LCD 집단만이 유의한 차이를 보였으며 $(p<.01)$, $\mathrm{TND}$ 집단과 $\mathrm{TCD}$ 집단, $\mathrm{TCD}$ 집단과 $\mathrm{LCD}$ 집단 간에는 그 차이가 유의하지 않은 것으로 나타났다.

\section{논의 및 결론}

본 연구는 인지적 어려움이 없는 초등학교 저학년( 1,2 학년)과 중 학년(3, 4학년)의 TND, TCD, 그리고 $\mathrm{LCD}$ 집단을 대상으로 연결어 미 형태인식능력이 학년집단과 아동집단 간에 어떠한 차이와 추이 
를 보이는지 살펴보고자 하였다. 연구에 참여한 다문화가정 아동 은 어머니의 국적이 국내에서 가장 많은 비율을 차지하는 중국, 일 본, 베트남, 필리핀의 4 개 국가로 제한하였고, 비다문화가정 아동들 과 어휘력상의 원점수가 유사하도록 일대일 매칭을 함으로써 문화 적 다양성이나 어휘력의 차이를 통제하고자 하였다. 연결어미 형태 인식 과제의 수행결과를 통계적으로 검증하기 위하여 먼저 아동집 단 내 학년 간 차이를 통해 학년에 따라 향상을 보이는지를 파악하 기 위해 비모수검정인 맨-휘트니 검정을 실시하였다. 또한 저학년 과 중학년에서 세 아동집단 간에 유의한 차이와 변화를 보이는지 를 분석하고자 각 학년별로 일원변량분석을 실시하였다. 연구결과 의 해석 및 그에 관한 논의는 다음과 같다.

첫째, 초등학교 저학년에서 중학년으로 학년이 증가함에 따라 연결어미에 대한 형태인식검사를 수행하는 능력은 다문화가정 배 경 유무나 언어지연 유무에 상관없이 모두 증진을 보였다. 이러한 결과는 학령기 아동의 파생어나 굴절어 형태인식이 학령기 초기에 본격적으로 나타나기 시작하여 초등학교 고학년 혹은 그 후까지 오랜 기간 꾸준히 발달하는 상위언어지식이라고 보고한 선행연구 들과 맥을 함께 한다(Anglin, 1993; Carlisle, 2000; Chung, 2016; Kirby et al., 2012; Lam \& Sheng, 2016; Nagy et al., 2006). 선행연구 에서 초등 1 학년의 경우 파생어와 굴절어에 관한 형태인식규칙을 이해하고 조작하는 과제를 수행할 수는 있었고 읽기능력과 약간의 관련성을 보였으나 그러한 관련성은 초등 3학년이 되면서 더 강력 해졌는데 연구자들은 형태인식과제 수행의 능숙성이 학년이 올라 갈수록 향상되었기 때문이라고 해석하였다(Kirby et al., 2012). 본 연구에서도 마찬가지로 형태소를 유추하고 조작하는 형태인식전 략을 능숙하게 적용하지 못하는 반응을 저학년 아동들이 중학년 아동들에 비해 자주 보였고 이는 상대적으로 낮은 평균수행점수로 확인할 수 있었다. 예컨대, 다문화배경 여부에 상관없이 정상발달 하는 저학년의 경우(TND, TCD 집단) '가다'를 '가면'으로 바꾸는 예시를 보고도 '씻으면' 대신 '씻면’이나 ‘도우면' 대신 '돕면'으로 답 하는 활용의 오류를 자주 보였으나, 중학년으로 올라갈수록 이러 한 오류를 보이지 않거나 스스로 수정하는 반응을 관찰할 수 있었 다. 그러나 흥미롭게도 언어지연 집단에 속한 아동들은( $\mathrm{LCD}$ 집단) 중학년에도 여전히 '씻면, ‘돕면'과 같은 오류를 지속하는 경우가 빈번히 관찰되었다. 이는 비록 어간에 어미(예: '-면')을 결합하는 형 태인식의 기본적인 전략이 발달하기는 하였으나 두 형태소가 결합 할 때 '으' 삽입이 일어나는 불투명한 활용의 유형에 관하여 완전히 습득하지 못한 일례로서, 학년에 따른 발달적 추이에도 불구하고 형태인식이라는 상위지식의 측면에서 여전히 취약성이 유지됨을 보여주고 있다.
이러한 취약성은 저학년과 중학년으로 나누어 세 집단이 보인 연 결어미 형태인식 수행능력 간의 차이를 분석하고 그 추이를 비교한 분석결과에서 더 드러난다. 사후검정결과 저학년, 즉 초등 1,2 학년 시기에는 다문화배경을 지닌 두 아동집단이 언어지연의 여부에 상 관없이 비다문화가정 배경을 지닌 아동집단에 비해 더 낮은 연결어 미 형태인식 수행능력을 보인 것으로 나타났다. 반면 중학년, 즉 초 등 3,4 학년 시기에는 정상적인 언어능력을 보이는 아동집단의 경 우 다문화가정 배경이나 비다문화가정 배경을 지닌 아동 간의 격차 가 저학년 시기보다 줄어들어 유의한 차이가 나타나지 않았다. 이 결과는 두 집단을 인지능력뿐 아니라 어휘력으로 대표되는 언어능 력에서도 원점수가 유사하도록 일대일로 매칭함으로써 두 집단이 다문화라는 요인에서만 차이를 보이도록 통제하였다는 점에서 시 사하는 바가 크다. 먼저, 학교환경에서 교과학습이 충분히 진행되 지 않은 저학년 아동에게는 어휘력보다 다문화배경이라는 요인이 연결어미 형태인식의 발달에 더 영향을 미치는 요인이라는 점이다. Jang 등(2014), Kim (2015), Kim과 Kim (2011) 등도 저학년 다문화 가정 아동들이 파생어 형태인식, 문법성 판단, 기타 상위언어능력 에서 여전히 어려움을 보인다고 보고한 바가 있다. 본 연구에서 사 용한 연결어미 형태인식 문항들은 상위언어적 전략을 적용해야 수 행이 가능하지만, 사전에 다양한 연결어미활용의 예들을 접한 경 험이 있는 아동들은 그 적용과 조작이 더 용이할 것이다. 그러나 다 문화가정 아동의 경우 주양육자인 어머니가 빈약한 한국어 기술 을 지닐 가능성이 높고, 어휘나 구문지식뿐 아니라 다양한 문법형 태소를 능숙하게 활용하는 데에도 제약을 보이는 경우가 많다 (Park, 2010). 따라서 종류가 많고 그 규칙을 습득하기가 어려운 언 어적 요소인 연결어미에 대한 학령전기의 경험이나 배경지식이 상 대적으로 부족한 저학년 다문화가정 아동들은 본 연구에서 보인 바와 같이 저조한 수행을 보일 수 밖에 없을 것이다. 반면 중학년, 즉 3,4 학년에서는 다문화가정 아동의 인지 및 언어능력이 비슷한 경우 비다문화가정 아동과 통계적으로 유의한 차이를 보이지 않는 것으로 나타났다. 비록 TCD 집단과 LCD 집단도 여전히 통계적인 유의도에서 차이를 보이지 않아 TCD 집단이 TND 집단에 비해 다 소 낮은 형태인식 기술을 지녔을 여지는 남아있다. 그러나 이러한 결과는 정상적인 언어기술을 지닌 다문화가정 아동이 저학년에 보 였던 저조한 수행은 언어지연이 아닌 언어적 차이에 의한 것이라는 실험적 증거가 될 수 있다. 즉, 저학년 시기에 보였던 집단 간의 차이 는 '다문화가정'이라는 용어가 내포하는 '문화적' 차이라기보다는 상대적으로 부족한 '언어적' 경험과 양에 기인한다는 의미이다.

둘째, 연구결과 동일한 다문화배경을 지녔음에도 언어적 지연을 보인 아동들은 정상적 언어기술을 지닌 다문화가정 아동집단과 달 
리 중학년에 이르러서도 TND 집단아동과 여전히 유의한 수행의 차이를 보인 것으로 나타났다. 초등 3,4 학년이 되면 교과학습을 통 해 명시적인 문법요소의 활용을 더 풍부하게 학습하게 되고 이는 형태인식전략의 적용을 촉진할 가능성을 높이지만, 기질적인 언어 장애 혹은 언어지연의 결과 낮은 어휘력을 보이는 아동은 언어적 자극이나 교과학습의 양이 동일하더라도 비다문화가정 아동의 형 태인식능력을 따라잡기에 역부족일 것이다. 따라서 이 연구결과는 연결어미 형태인식이 학년이나 연령이 증가함에 따라 아동이 경험 하는 환경적 입력의 양이나 교육적 경험에 의해 성취할 수 있는 능 력이라기보다는 아동이 지닌 타고난 언어처리능력이나 어휘력 등 과 좀 더 관련된 상위언어기술이라는 해석을 가능하게 한다(Bowers \& Kirby, 2010; Carlisle, 2000; Chung, 2017; Kieffer \& Lesaux, 2008; Kuo \& Anderson, 2006; Ramirez et al., 2014).

본 연구결과를 통해 표준화된 어휘검사 결과 정상범주에 있는 다문화가정 아동은 언어지연을 보인 다문화가정 아동에 비해 연령 이나 학년이 증가할수록 비다문화가정 아동과 유사한 연결어미 형 태인식 수행능력을 보이는 것을 알 수 있었다. 달리 해석하면 언어 지연을 보인 다문화가정 아동은 학년의 증가에도 여전히 연결어미 형태인식 과제를 수행하는 데에 취약성을 보였으며, 이는 연결어미 를 조작하는 형태인식능력이 환경적 입력에 의해 자연스럽게 습득 되고 성취되는 상위언어기술이 아니라는 점을 확인한 연구결과였 다. 이러한 결과는 이 아동들이 다문화가정이라는 환경과 상관없 이 이미 언어학습장애 혹은 단순언어장애를 지녔을 가능성도 내포 한다. 그렇기에 이 상위언어기술에 관한 심도 깊은 탐색을 위해 다 양한 언어장애군을 대상으로 진행하는 후속연구가 필요할 것이다.

또한 이 연구는 다문화가정 아동을 평가하는 데 있어서 형태인 식 과제가 지니는 적용가능성과 이들을 중재하는 데 있어서 명시적 인 형태인식 중재교수가 저학년 시기부터 이루어져야 함을 시사한 다. 그러나 본 연구는 언어지연 아동을 구문이 아닌 어휘력의 측면 에서만 분류하였고, 종단연구가 아닌 횡단연구로 진행되었으며 아 동집단 내 학년마다 포함된 아동의 수가 적었기에 그 결과를 제한 적으로 해석할 필요가 있다. 또한 본 연구는 1 학년에서 4 학년을 대 상으로 실시하였으나 5,6 학년 및 청소년을 포함하여 문화적 배경 에 대한 영향을 폭넓게 살펴볼 뿐더러 어휘의 깊이와 질에 관한 지 식, 구문을 이해하고 판단하는 지식 등과 비교한 추후연구가 필요 할 것으로 사료된다.

\section{REFERENCES}

Anglin, J. M. (1993). Vocabulary development: a morphological analysis.
Monographs of the Society for Research in Child Development, 58(10), 1-186.

Bowers, P. N., \& Kirby, J. R. (2010). Effects of morphological instruction on vocabulary acquisition. Reading and Writing, 23(5), 515-537.

Brice, A., \& Montgomery, J. (1996). Adolescent pragmatic skills: a comparison of Latino students in English as a second language and speech and language programs. Language, Speech, and Hearing Services in Schools, 27(1), 68-81.

Carlisle, J. F. (1995). Morphological awareness and early reading achievement. In L. B. Feldman (Ed.), Morphological aspects of language processing (pp. 189-209). Hillsdale, NJ: Lawrence Erlbaum Associates.

Carlisle, J. F. (2000). Awareness of the structure and meaning of morphologically complex words: impact on reading. Reading and Writing, 12(3), 169190.

Cha, E. H., Hwang, M. A., \& Jeong, M. R. (2019). Verb conjugating in Korean children with mild intellectual disabilities. Journal of Speech-Language \& Hearing Disorders, 28(1), 29-36.

Chang, Y. R. (2011). Comparative study on the characteristics of connective endings between children from multicultural and non-multicultural backgrounds: focused on the first and third-graders in elementary schools (Master's thesis). Yongin University, Yongin, Korea.

Choi, M. H. (2011). The production of case particles and semantic particles of korean preschool children from multicultural family and non-multicultural family (Master's thesis). Dankook University, Yongin, Korea.

Choi, S., \& Shin, M. J. (2018). The characteristic of word definition in schoolage children with high-functioning autism spectrum disorder. Journal of the Korean Association for Persons with Autism, 18(2), 121-141.

Choi, S. A., \& Hong, K, H. (2012). Assessing the idiom comprehension abilities of 5th and 6th grade students from multi-cultural families. Special Education Research, 11(3), 167-187.

Chung, B. J. (2013). Connective endings of 2 to 5 year-old typically developing children. Korean Journal of Early Childhood Special Education, 13(4), 233-246.

Chung, B. J. (2016). Morphological awareness on derivational affixes and related variables in school-aged children (Doctoral dissertation). Ewha Womans University, Seoul, Korea.

Chung, B. J. (2017). Relations between morphological awareness and vocabulary in first and second graders. Journal of Learner-Centered Curriculum and Instruction, 17(9), 541-552.

Deacon, S. H., \& Kirby, J. R. (2004). Morphological awareness: just "more phonological"? The roles of morphological and phonological awareness in 
reading development. Applied Psycholinguistics, 25(2), 223-238.

Fehring, R. J. (1987). Methods to validate nursing diagnoses. Heart and Lung, 16(6 PT 1), 625-629.

Gibson, F. E., \& Wolter, J. A. (2015). Morphological awareness intervention to improve vocabulary and reading success. Perspectives on Language Learning and Education, 22(4), 147-155.

Goldstein, B. A., Fabiano, L., \& Washington, P. S. (2005). Phonological skills in predominantly English-speaking, predominantly Spanish-speaking, and Spanish-English bilingual children. Language, Speech, and Hearing Services in Schools, 36(3), 201-218.

Green, L. (2009). Morphology and literacy: getting our heads in the game. Language, Speech, and Hearing Services in Schools, 40(3), 283-285.

Hwang, D. J., Hwang, M. A., \& Lim, J. A. (2019). Drawing inferences from the presuppositions of sentences in children from multicultural families. Special Education Research, 18(1), 257-271.

Im, Y. J., \& Lee, P. Y. (2004). The developmental stages of connective expressions in the utterances of Korean Students. The Text Linguistic Society of Korea, 17, 173-200.

Jang, J., Jeong, M., \& Hwang, M. (2014). Comprehending and defining homonyms in school-aged children from multicultural families. Communication Sciences \& Disorders, 19(1), 71-79.

Jang, M., \& Kim, J. M. (2014). Use of connective endings as a connective function and connective endings as a final function in the spontaneous language of typically developing preschoolers. Journal of Speech \& Hearing Disorders, 23(4), 89-100.

Jeong, E. H., Kim, T. G., \& Park, Y. (2012). A study on assessment and language development characteristics of children from multicultural families. The Journal of Special Children Education, 14(3), 113-141.

Jo, C. H., Hwang, M. A., \& Jeong, M. R. (2018). The collocation abilities of school-aged children from multicultural families. Journal of Speech-Language \& Hearing Disorders, 27(1), 83-97.

Jung, K. H. (2014). Morphological awareness and reading ability of schoolaged children from grades 1 to 3. Communication Sciences \& Disorders, 19(1), 21-30.

Kieffer, M. J., \& Lesaux, N. K. (2008). The role of derivational morphology in the reading comprehension of Spanish-speaking English language learners. Reading and Writing, 21(8), 783-804.

Kieffer, M. J., \& Lesaux, N. K. (2012). Development of morphological awareness and vocabulary knowledge in Spanish-speaking language minority learners: a parallel process latent growth curve model. Applied Psycholin- guistics, 33(1), 23-54.

Kim, E. H., \& Jung, K. H. (2015). Morphological awareness of 1st to 3rd grade school-aged children from multicultural families. Communication Sciences \& Disorders, 20(2), 319-330.

Kim, E. J., \& Kim, H. S. (2011). Comparison on grammaticality judgement and error correction abilities between children in ordinary and in multicultural families. Journal of Special Education \& Rehabilitation Science, 50(2), 131-148.

Kim, G. E. (2015). Morphological awareness of connective endings in first and second grade poor readers (Master's thesis). Chosun University, Gwangju, Korea.

Kim, G. E., \& Chung, B. J. (2017). Morphological awareness of connective endings in first and second grade poor readers. Journal of Speech-Language \& Hearing Disorders, 26(2), 77-88.

Kim, K. H. (2003). Grade level vocabulary list. Seoul: Pagijung.

Kim, S. Y. (2012). The comprehension and production of tense markings in Korean preschool children from multicultural family and non-multicultural family (Master's thesis). Dankook University, Yongin, Korea.

Kim, Y. R., \& Lee, H. J. (2016). Vocabulary and literacy skills of Korean schoolaged children from multicultural backgrounds. The Journal of Humanities and Social Sciences 21, 7(6), 263-279.

Kim, Y. T., Hong, G. H., Kim, K. H., Jang, H. S., \& Lee, J. Y. (2009). Receptive \& expressive vocabulary test (REVT). Seoul: Seoul Community Rehabilitation Center.

Kirby, J. R., Deacon, S. H., Bowers, P. N., Izenberg, L., Wade-Woolley, L., \& Parrila, R. (2012). Children's morphological awareness and reading ability. Reading and Writing, 25(2), 389-410.

Kirk, C., \& Gillon, G. T. (2009). Integrated morphological awareness intervention as a tool for improving literacy. Language, speech, and Hearing Services in Schools, 40(3), 341-351.

Kouider, E. B., Koglin, U., \& Petermann, F. (2015). Emotional and behavioral problems in migrant children and adolescents in American countries: a systematic review. Journal of Immigrant and Minority Health, 17(4), 12401258.

Kuo, L. J., \& Anderson, R. C. (2006). Morphological awareness and learning to read: a cross-language perspective. Educational Psychologist, 41(3), 161180.

Kwon, J. I. (2009). Research of the vocabulary of elementary school textbooks. Seoul: National Institute of Korean Language.

Lam, B. P. W., \& Sheng, L. (2016). The development of morphological aware- 
ness in young bilinguals: effects of age and L1 background. Journal of Speech, Language, and Hearing Research, 59(4), 732-744.

Lee, H. J., \& Kim, M. (2015). The correlation between metaphor comprehension and reading comprehension of poor readers in 4-6 grades. Communication Sciences \& Disorders, 20(2), 331-343.

McBride-Chang, C., Tardif, T., Cho, J. R., Shu, H. U. A., Fletcher, P., Stokes, S. F., ... \& Leung, K. (2008). What's in a word? Morphological awareness and vocabulary knowledge in three languages. Applied Psycholinguistics, 29(3), 437-462.

Ministry of the Interior and Safety. (2015). The survey of foreign population. https://www.mois.go.kr/frt/bbs/type001/commonSelectBoardArticle.do?b bsId=BBSMSTR_000000000014\&nttId=46327

Nagy, W., Berninger, V. W., \& Abbott, R. D. (2006). Contributions of morphology beyond phonology to literacy outcomes of upper elementary and middle-school students. Journal of Educational Psychology, 98(1), 134-147.

Nagy, W. E., \& Anderson, R. C. (1999). Metalinguistic awareness and literacy acquisition in different languages. In D. A. Wagner et al. (Eds.), Literacy: an international handbook (pp. 155-160). Boulder, CO: Westview Press.

Park, E. J. (2010). Research on maternal linguistic input and Korean language development phases of children from multicultural families (Doctoral dissertation). Keimyung University, Daegu, Korea.

Park, H. (2014). Korean version of Comprehensive Test of Nonverbal Intelligence Second Edition (K-CTONI-2). Seoul: Mindpress.

Park, J. H., Kim, Y. T., \& Yeon, S. J. (2018). Connective ending awareness of early school-aged children at risk for specific language impairment. Communication Sciences \& Disorders, 23(4), 879-889.

Ramirez, G., Walton, P., \& Roberts, W. (2014). Morphological awareness and vocabulary development among kindergarteners with different ability levels. Journal of Learning Disabilities, 47(1), 54-64.

Song, E. J., \& Kim, W. S. (2011). Production of connective endings for children of multi-cultural family. Contemporary Society and Multiculture, 1(1), 218-238.

Song, J. K. (2016). Conjunctive endings and function-converting endings in school grammar. The Korean Language and Literature, 68, 141-165.

Sparks, E., \& Deacon, S. H. (2015). Morphological awareness and vocabulary acquisition: a longitudinal examination of their relationship in Englishspeaking children. Applied Psycholinguistics, 36(2), 299-321.

Weiss, L. G., Saklofske, D. H., Prifitera, A., \& Holdnack, J. A. (2006). WISCIV advanced clinical interpretation. Burlington, MA: Academic Press.

Wolter, J. A., \& Dilworth, V. (2014). The effects of a multilinguistic morphological awareness approach for improving language and literacy. Journal of Learning Disabilities, 47(1), 76-85.

Yi, B. W. (2015). Korean grammar for speech-language pathologists. Seoul: Hakjisa.

Zhang, D., Koda, K., \& Leong, C. K. (2016). Morphological awareness and bilingual word learning: a longitudinal structural equation modeling study. Reading and Writing, 29(3), 383-407. 
Appendix 1. Examples of morphological awareness test

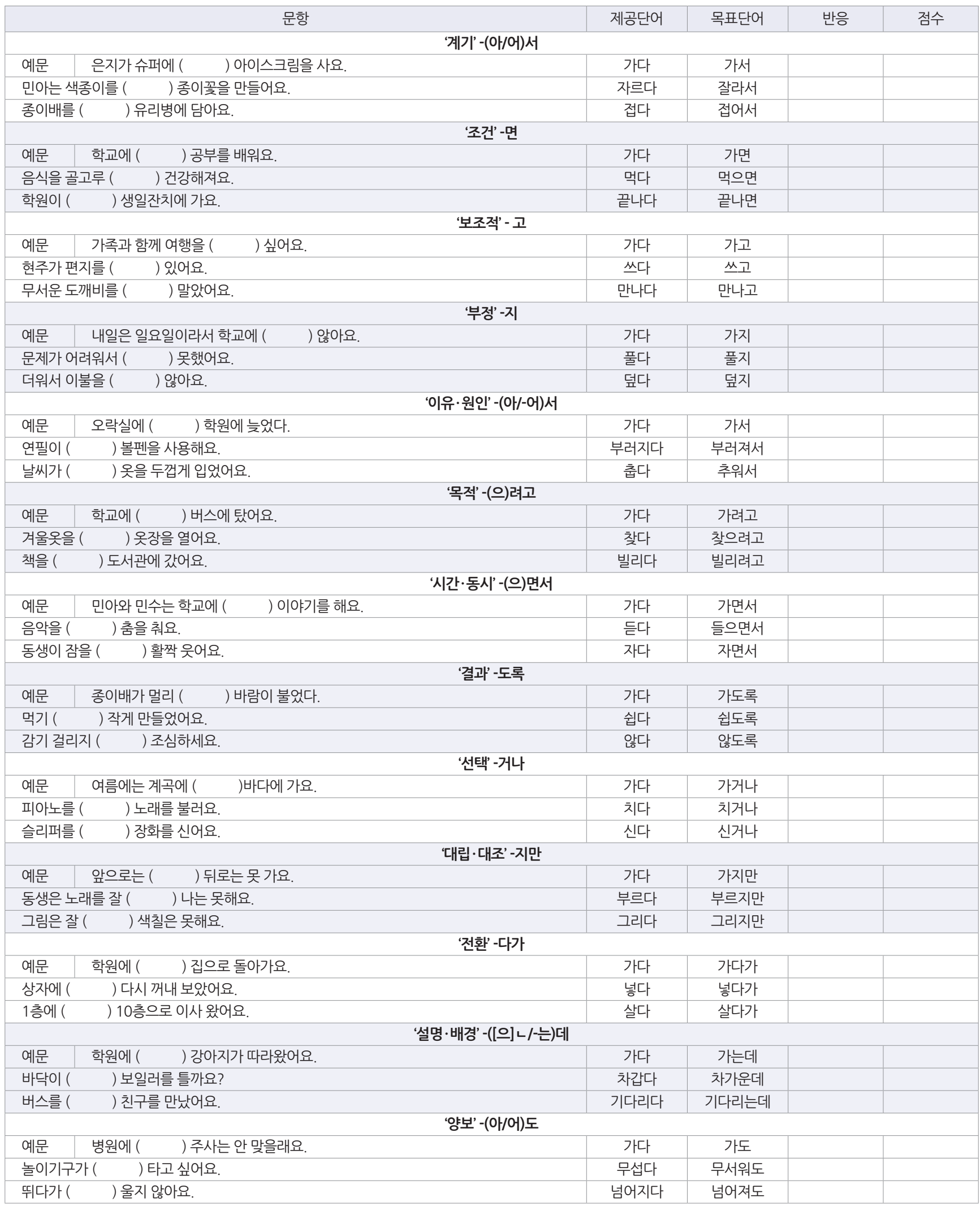




\section{국문초록}

\section{초등학교 1-4학년 다문화가정아동의 연결어미 형태인식 특성 \\ 심승은 $\cdot$ 정부자 ${ }^{2}$ \\ 1한국아동가족상담센터, ${ }^{2}$ 조선대학교 보건과학대학 언어치료학과}

배경 및 목적: 국내의 다문화 인구가 급격하게 증가함에 따라 다문화가정 아동들이 비다문화가정 아동들에 비해 상대적으로 적절한 언어자극을 받지 못한다는 우려와 함께 다양한 언어적 영역의 평가 및 중재의 필요성이 대두되고 있다. 형태인식은 학령기 아동들의 언 어 및 읽기능력을 평가하고 중재하는 데에 있어 중요한 요소로 여겨지고 있다. 따라서 본 연구에서는 연결어미 형태인식이 다문화배경 이나 언어능력에 따라 어떠한 차이를 보이는지, 학년에 따라 어떠한 발달적 변화를 보이는지 살펴보고자 하였다. 방법: 초등학교 저학 년(1-2학년)과 중학년(3-4학년)의 비다문화가정 정상언어아동(TND), 다문화가정 정상언어아동(TCD), 다문화가정 언어발달지연아 동(LCD)을 대상으로 타당성이 검증된 연결어미 형태인식검사를 실시하였다. 결과: TCD 집단과 TND 집단은 저학년에서 연결어미 형 태인식능력에 유의한 차이를 보였으나 중학년에서는 차이를 나타내지 않았다. 반면 LCD 집단은 모든 학년에서 TND 집단에 비해 유의 하게 낮은 연결어미 형태인식능력을 보였다. 또한 모든 집단이 학년이 높아짐에 따라 연결어미 형태인식능력이 증가하였지만 LCD 집단 은 학년이 증가하였음에도 TCD 집단과 TND 집단에 비해 여전히 유의하게 낮은 점수를 보였다. 논의 및 결론: 본 연구의 결과는 저학 년이라는 시기에는 다문화배경이라는 요소가 아동의 연결어미 형태인식능력에 영향을 미쳤지만 학년이 증가함에 따라 문화적 배경보 다는 어휘력이라는 언어적 요소가 형태인식과 더욱 관련이 있음을 보여주었다. 따라서 저학년 시기부터 다문화가정 아동들에게 형태 인식에 관한 명시적 교수가 제시될 필요가 있다.

핵심어: 연결어미 형태인식, 다문화가정아동, 어휘, 학령기

본 논문은 2018학년도 조선대학교 학술연구비의 지원을 받아 연구되었음.

본논문은 제 1 저자의 석사학위 논문을수정·보완한 것임.

\section{참고문헌}

권재일(2009). 초등학교 교과서 어휘조사연구. 서울: 국립국어원.

김가은(2015). 초등학교 1-2학년 읽기부진아동의 연결어미 형태인식 능력. 조선대학교 대학원 석사학위논문.

김가은, 정부자(2017). 초등학교 1-2학년 읽기부진아동의 연결어미 형태인식 특성. 언어치료연구, 26(2), 77-88.

김광해(2003). 등급별 국어교육용 어휘. 서울: 박이정.

김성이(2012). 학령전 다문화가정 아동과 일반가정 아동의 시제표지의 이해와산출. 단국대학교 대학원 석사학위논문.

김영태, 홍경훈, 김경희, 장혜성, 이주연(2009). 수용·표현어휘력검사(REVT). 서울: 서울장애인종합복지관.

김유리, 이현정(2016). 학령기 다문화가정 아동의 언어발달 특성: 어휘력과 문해능력을 중심으로. 인문사회21, 7(6), 263-279.

김은정, 김화수(2011). 다문화가정 아동과 일반 아동의 문법성 판단 및 오류수정 비교 연구. 특수교육재활과학연구, 50(2), 131-148.

김은하, 정경희(2015). 초등 1-3학년 다문화가정 아동의 형태소인식능력. Communication Sciences \& Disorders, 20(2), 319-330.

박은정(2010). 어머니 언어입력과 다문화가정 자녀의 한국어 발달 과정 연구. 계명대학교 대학원 박사학위논문.

박지혜, 김영태, 연석정(2018). 초등학교 저학년 단순언어장애 위험 아동의 연결어미 인식 능력. Communication Sciences \& Disorders, 23(4), 879-

889.

박혜원(2014). 한국 비언어지능검사 2판(K-CTONI-2). 서울: 마인드프레스.

송은주, 김화수(2011). 다문화가정 아동의 연결어미 사용에 관한 연구. 현대사회와다문화, 1(1), 218-238.

송정근(2016). 학교 문법의 연결 어미와 전성 어미. 우리말 글, 68, 141-165. 
이봉원(2015). 언어치료사를 위한 한국어문법. 서울: 학지사.

이현정, 김미배(2015). 4-6학년 읽기부진아동의 은유이해능력과 읽기이해능력의 상관관계. Communication Sciences \& Disorders, 20(2), 331-343.

임유종, 이필영(2004). 한국 초·중·고등학생의 발화에 나타난 연결표현의 발달 단계. 텍스트언어학, 17, 173-200.

장미, 김정미(2014). 2-5세 일반아동의 자발화에 나타난 연결 기능 연결어미와 종결 기능 연결어미 사용 특성. 언어치료연구, 23(4), 89-100.

장유림(2011). 다문화가정과 일반 가정 아동의 연결어미 특성 비교: 초등학교 1학년,3학년을 중심으로. 용인대학교 대학원 석사학위논문.

장종윤, 정미란, 황민아(2014). 초등학교 저학년 다문화가정 아동의 동음이의어 이해와 정의하기. Communication Sciences \& Disorders, 19(1), 71-

79.

정경희(2014). 1-3학년 학령기 아동의 형태소인식과 읽기능력. Communication Sciences \& Disorders, 19(1), 21-30.

정부자(2013).2세에서 5세 일반아동의 자발화에 나타난 연결어미 발달 특성. 유아특수교육연구, 13(4), 233-246.

정부자(2016). 초등학교 저학년과 중학년 일반아동의 파생어 형태인식 발달 및 예측 변인 탐색. 이화여자대학교 대학원 박사학위논문.

정부자(2017). 초등학교 1-2학년 아동의 어휘력에 따른 형태인식 특성. 학습자중심교과교육연구, 17(9), 541-552.

정은희, 김태강, 박윤(2012). 다문화가정 아동의 언어발달 특성과 진단.평가에 대한 문헌 고찰. 특수아동교육연구, 14(3), 113-141.

조총희, 황민아, 정미란(2018). 학령기 다문화가정 아동과 일반가정 아동의 연어(連語) 능력. 언어치료연구, 27(1), 83-97.

차은혜, 황민아, 정미란(2019). 경도 지적장애 아동의 용언 활용. 언어치료연구, 28(1), 29-36.

최미현(2011). 학령전 다문화가정 아동과 일반가정 아동의 격조사와보조사산출 비교. 단국대학교 대학원 석사학위논문.

최송아. 홍경훈(2012). 초등학교 5-6학년 다문화가정 아동과 일반가정 아동의 관용어 이해 능력 비교분석. 특수교육, 11(3), 167-187.

최숲, 신문자(2018). 학령기 고기능 자폐스펙트럼장애 아동의 낱말 정의하기 특성. 자폐성장애연구, 18(2), 121-141.

행정안전부(2015). 외국인 주민 현황조사. https://www.mois.go.kr/frt/bbs/type001/commonSelectBoardArticle.do?bbsId= BBSMSTR_000000000

014\&nttId $=46327$

황다정, 황민아, 임종아(2019). 초등학교 2-3학년 다문화가정 아동의 전제 의미 추론 능력. 특수교육, 18(1), 257-271.

\section{ORCID}

심승은(https:///orcid.org/0000-0002-5306-3019); 정부자(https://orcid.org/0000-0002-6158-6637) 